Abstract

\title{
A Novel Sensor for a Bio-Mimetic Finger ${ }^{\dagger}$
}

\author{
Tayachew Fikire Agidew *, Emanuele Lindo Secco *, Andualem Tadesse Maereg, \\ Mark Baxendale, David Reid and Atulya Kumar Nagar \\ Robotics Laboratory, Department of Mathematics \& Computer Science, Liverpool Hope University, \\ Liverpool L16 9JD, UK; maerega@hope.ac.uk (A.T.M.); mark.baxendale@hope.ac.uk (M.B.); \\ reidd@hope.ac.uk (D.R.); nagara@hope.ac.uk (A.K.N.) \\ * Correspondence: agidewt@hope.ac.uk (T.F.A.); seccoe@hope.ac.uk (E.L.S.) \\ + Presented at the 5th International Symposium on Sensor Science (I3S 2017), Barcelona, Spain, \\ 27-29 September 2017.
}

Published: 4 December 2017

We have designed and integrated a novel fibre-optic based sensor for force discrimination on a biomimetic finger. The sensor is free of any metallic and electrical components and immune to electromagnetic disturbances. A cantilever mechanism was designed in order to embed the sensor at the fingertip of the finger phalange. The design has been optimized by Finite Element Analysis (FEA). The biomimetic finger has been manufactured using Acrylonitrile-Butadiene-Styrene (ABS) via 3D printing processes. Two optical fibres (i.e., SH1001-1.0 Eska Super PE jacket), and light reflective surface are integrated at the tip of the phalange. Sensor calibration has been conducted using a digital optical amplifier (i.e., Keyence FS-N11MN), USB National Instruments DAQ card (NI USB-6000) and a six-axis Force and Torque sensor (F/T IIT-FT17).

The sensor was mounted on a linear guide in order to face the IIT-FT17 force sensor on its longitudinal axis. Software setup has been developed based on LabVIEW and C++. The loading and unloading experiments were performed and force and corresponding voltage values have been logged using the developed software setup. Regression analysis shows high correlation between the two data (i.e., force and voltage) with coefficient of determination $\left(R^{2}=0.97\right)$. Based on the calibration result, the sensor has better sensitivity (i.e., $097 \mathrm{~V} / \mathrm{N}$ ), an input range of $[0-5 \mathrm{~N}]$ and resolution of $0.02 \mathrm{~N}$.

Unlike other sensors, this sensor's biocompatible design, simplicity and reliability make it ideal for challenging working environments (high voltage and electromagnetic noise).

(C) 2017 by the authors. Licensee MDPI, Basel, Switzerland. This article is an open access article distributed under the terms and conditions of the Creative Commons Attribution (CC BY) license (http://creativecommons.org/licenses/by/4.0/). 